(2) OPEN ACCESS

\title{
Blunt duct adenosis: a separate entity from columnar cell lesions?
}

\author{
Mirthe de Boer, Paul J van Diest
}

Pathology, University Medical Center Utrecht, Utrecht, The Netherlands

\section{Correspondence to}

Professor Paul J van Diest, Pathology, UMC Utrecht, Utrecht, Netherlands; p.j. vandiest@umcutrecht.nl

Received 21 December 2020 Revised 24 February 2021 Accepted 25 February 2021
D) Check for updates

(C) Author(s) (or their employer(s)) 2021. Re-use permitted under CC BY-NC. No commercial re-use. See rights and permissions. Published by BMJ.

To cite: de Boer $M$, van Diest PJ. J Clin Pathol Epub ahead of print: [please include Day Month Year]. doi:10.1136/

jclinpath-2020-207359

\section{ABSTRACT}

Blunt duct adenosis (BDA) is a breast lesion first described by Foote and Stewart in 1945 as a proliferative benign lesion of the terminal duct lobular unit.

Throughout recent decades, further literature descriptions of BDA have been confusing. Some consider BDA to be a separate entity, some a growth pattern of columnar cell changes. The WHO 2012 considered BDA and columnar cell changes to be synonyms, while columnar cell lesions, especially those with atypia, are part of a spectrum of early precursors of the low nuclear grade breast neoplasia family. In the updated WHO 2019 version, BDA is mentioned as 'not recommended' terminology for columnar cell lesions without further discussing it, leaving the question open if BDA should be considered a separate entity.

Good diagnostic criteria for BDA have however largely been lacking, and its biological background has not yet been unravelled. In this paper, we point out that BDA is mainly associated with benign breast lesions and not with other recognised precursor lesions. Further, $16 q$ loss, which is the hallmark molecular event in the low nuclear grade breast neoplasia family, is lacking in $\mathrm{BDA}$. We therefore hypothesise that BDA may not be a true precursor lesion but a benign polyclonal lesion, and propose morphological diagnostic criteria to better differentiate it from columnar cell lesions.

\section{INTRODUCTION}

The human breast displays a broad spectrum of benign proliferative lesions. They are seen frequently and do not indicate an increased risk of breast cancer and therefore need to be discriminated from proliferative clonal breast lesions that are early precursors of invasive breast cancer. For many benign proliferative lesions, such as adenosis, apocrine metaplasia, usual ductal hyperplasia, sclerosing lobular hyperplasia and ductectasias, diagnostic criteria have been well defined these lesions do not often pose diagnostic dilemmas on the practising pathologist. An exception is blunt duct adenosis (BDA) that has caused confusion because of the varying terminology used in literature and the lack of a clear definition based on well-defined diagnostic criteria. Also, the relation with early precursors of the low nuclear grade breast neoplasia family like columnar cell lesions (CCLs) is unclear.

Here, we review the criteria for the diagnosis of BDA put forward by different authors, evaluate its biological background. This leads to the hypothesis that BDA may not be a true precursor lesion but a benign polyclonal lesion that needs to be discriminated from CCLs, for which we propose morphological diagnostic criteria.

\section{MORPHOLOGICAL DESCRIPTIONS AND INTERPRETATION OF BDA IN THE LITERATURE}

The earliest description of BDA was by Foote and Stewart in $1945^{1}$ as a lesion affecting small or large areas of the breast tissue with formation of cysts in some cases. They postulated that BDA originated from terminal ducts with obliteration of the lobules as the process expands to dilated lobules.

In 1976, Azzopardi more extensively described $\mathrm{BDA}$ as a proliferative benign lesion of the enlarged terminal duct lobular unit (TDLU) not indicating increased risk of malignancy. ${ }^{2}$ The lesion was conceptually viewed as 'organoid hypertrophy', with acini that are not increased in number but in size, with hyperplasia of the epithelium and increased intralobular stroma, and a prominent myoepithelial layer was illustrated in pictures. $\mathrm{He}$ also described non-organoid and microcystic forms of BDA.

In the scientific literature concerning CCLs, BDA was in the past often considered as a synonym or a growth pattern of CCL, ${ }^{34}$ independent of atypia. Shaaban et al described different subtypes of BDA (BDA not otherwise specified, BDA with calcifications, BDA with columnar cell metaplasia, BDA with atypical columnar cell metaplasia, BDA with usual ductal hyperplasia (UDH) and BDA with atypical ductal hyperplasia $(\mathrm{ADH}))^{3}{ }^{3}$ In line with this, Kunju et al described that the most common morphological pattern (52\%) of flat epithelial atypia (FEA) was that of BDA. ${ }^{4}$ This is a good illustration of the overlap in terminology between BDA and CCL.

The WHO Classification of tumours of the breast, 2012 Edition, considers BDA as a synonym of columnar cell change (CCC)/hyperplasia (CCH), a category for which cytological atypia is not a feature. ${ }^{5}$ Thereby, BDA was distinguished from FEA, for which cytonuclear atypia is the hallmark feature. This is also adopted in most recent textbooks about breast pathology, usually without further morphological descriptions. The 2019 WHO edition, however, clearly states in a chapter 'Columnar cell lesions including flat epithelial atypia' that BDA is 'not recommended terminology' for $\mathrm{CCL}^{6}$ without further discussing BDA, leaving the question open whether it should be considered a separate entity. The histopathology description of columnar cell change by the WHO mentions "The involved acini usually have irregular contours", while we consider irregular contours to be rather a feature of BDA (see below), while the acini involved 
by FEA are described by the WHO to 'usually have smooth contours'. Nevertheless, in some textbooks, we found a more detailed description of BDA, and also different types or different stages of BDA were distinguished.

Brogi described BDA in Rosen's breast pathology ${ }^{7}$ as a form of terminal duct hyperplasia characterised by abortive lobule formation, referring to the first description of Foote et al. Also some typical characteristics were mentioned, containing conspicuous myoepithelial cells with often abundant clear cytoplasm and slightly expanded, fibrotic and cellular intralobular stroma. Only the cystically dilated variant was described to simulate FEA.

Koerner ${ }^{8}$ included two different lesions in the term BDA, the first one described by Foote and Steward, which in his opinion could not be confused with FEA. The second lesion included lobular hypertrophy with dilated glands, which can mimic FEA, probably similar to the microcystic form described by Azzopardi. ${ }^{2}$ Koerner pointed out some differences between BDA and FEA like the flattened branching configurations in BDA in contrast to the round globular shapes in FEA, the prominent continuous myoepithelial layer in BDA which is incomplete and not conspicuous in FEA, and the cellular myxoid stroma of early BDA, while FEA stroma lacks these reactive features. At the same time, it was mentioned that in the early proliferative phase of BDA, the luminal cells have columnar features, abundant apical cytoplasm and slightly enlarged round nucleoli, and calcium deposits may be present, resembling FEA.

The book of Palazzo provided a chapter written by Lerwill with a comprehensive text on FEA including the differential diagnosis with BDA. ${ }^{9}$ In the early proliferative phase of BDA, cells are described to be columnar with mildly enlarged and atypical nuclei comparable to the nuclei of UDH, dilated acini of branching shape and expanded intralobular stroma. Also an inactive phase of BDA was described, with more rounded acini in which the luminal cells have a stubby columnar or cuboidal shape, minimal cytoplasm and the nuclei are hyperchromatic with inconspicuous nucleoli, and more fibrotic stroma. Very illustrative pictures and a rather complete table with criteria to discriminate BDA from FEA were provided.

Also in the book of Dabbs, several subtypes of BDA were described, like a BDA with $\mathrm{CCC} / \mathrm{CCH}$ lining, apocrine BDA and BDA of no special type. ${ }^{10}$

\section{BDA AND ASSOCIATIONS WITH OTHER BREAST LESIONS}

BDA has been described to be often associated with other benign proliferative lesions. BDA lesions have been described to regularly show apocrine changes. ${ }^{70}$ Morphological overlap with UDH or foci of UDH in BDA have also been reported. ${ }^{910}$ Only Foote and Stewart in $1945^{1}$ support the association of BDA and benign cystic and proliferative lesions with data. It has been described that FEA may arise in a BDA background ${ }^{11}$ but detailed morphological observations suggest that FEA more likely arises in structurally normal TDLU, ${ }^{12}$ independent of BDA, which is also our experience.

Although the association of CCL without atypia and other family members of the low nuclear grade breast neoplasia family, like lobular neoplasia (LN) and tubular carcinoma, has been described, ${ }^{13}{ }^{14}$ we rarely observe such association for BDA.

\section{IMMUNOHISTOCHEMICAL PROFILE OF BDA}

Proposals for differentiating between BDA and FEA with immunohistochemical stainings have been put forward in several papers. BDA luminal cells express glandular keratins such as CK7, CK8 or CK18. CK5 and CK14 should display a mosaic pattern especially by small knots of hyperplastic cells protruding into the lumen, while CCLs are clonally negative. ${ }^{910}$ Oestrogen receptor- $\alpha(E R \alpha)$ is often expressed in a high percentage of the luminal cells of BDA, so this does not help much to discriminate $\mathrm{BDA} \mathrm{ER} \alpha$ patterns from the (clonally) positive ER $\alpha$ expression in CCL. ${ }^{9}$ There seems to be less cyclin D1 expression in BDA compared with CCL with atypia/FEA, although not all CCLs are cyclin D1 positive. ${ }^{15}$ In our own practice, we usually see a quite low number of CK5 and CK14 positive cells in flat parts of BDA, while ER $\alpha$ is expressed in the majority of cells, meaning that there is no striking mosaic pattern and the lesion can be misinterpreted as clonal. In BDA with areas of UDH with more luminal proliferating cells, the immunohistochemical profile more clearly points towards a polyclonal proliferation. Altogether, immunohistochemical stainings do therefore not seem to play a major role in differentiating CCLs and BDA.

\section{MOLECULAR STUDIES ON BDA}

Molecular studies on BDA are difficult to identify because of the varying terminology used. It is especially difficult to find out if there are differences in molecular background between CCLs (without atypia) and BDA because likely, in some molecular studies on CCLs, cases of BDA as we define them have been included as CCL without atypia. Regarding to CCLs without atypia, Simpson et al studied 14 cases of CCL without hyperplasia and atypia that unlikely included BDA lesions (which are usually small) since enough DNA could be isolated for comparative genomic hybridisation (CGH) analysis. Four of these 14 CCLs showed loss of $16 \mathrm{q}$ by $\mathrm{CGH},{ }^{16}$ suggesting the studied CCLs are low nuclear grade breast neoplasia family precursors despite absence of atypia. On the other hand, Go et al did not find deletions of $16 \mathrm{q}$ in CCLs without atypia. ${ }^{17}$

Our own study with well-defined BDA cases applying copy number multiplex ligation-dependent probe amplification for chromosome 16 showed no whole arm losses of $16 \mathrm{q}$ in 10 welldefined BDA cases, while 16q losses were common in CCLs with and without atypia. ${ }^{18}$

Altogether, these scarce data do not seem to point to clonal (premalignant) changes in BDA, in contrast to the CCLs with and without atypia.

\section{BDA: A SEPARATE ENTITY?}

Most authors of the described studies use BDA as a synonym of, or entity within the group of, CCL without atypia, and thereby discriminate BDA from CCL with atypia/FEA. This was endorsed by the WHO Classification of tumours of the breast up to the 2012 Edition. The 2019 WHO edition, however, clearly states that BDA is 'not recommended terminology' for CCL. ${ }^{6}$ We have provided several arguments that BDA may differ from CCL without atypia in the above. Using morphological characteristics (see next paragraph), BDA can, in our opinion, also well be separated from other lesions in this group. The role of CCL without atypia in breast carcinogenesis may have been questioned, but the $2019 \mathrm{WHO}^{6}$ states that "given that they (ie, CCL with- and without atypia) share immunophenotypic and molecular alterations with other lesions in the low-grade breast neoplasia pathway, it is reasonable to speculate that their etiology is similar". Not only the associations between CCL and lesions from the low-grade nuclear breast neoplasia family have been described, ${ }^{1314}$ also similar molecular alterations were found in CCL with and without atypia. ${ }^{16}{ }^{18}$ Especially chromosome $16 \mathrm{q}$ loss was found repeatedly, pointing towards a precursor role of both lesions in low nuclear grade breast carcinogenesis. ${ }^{19}$ 
Table 1 Differential diagnosis of blunt duct adenosis (BDA) vs columnar cell lesion (CCL) with and without atypia

\begin{tabular}{|c|c|c|c|}
\hline & CCL without atypia & CCL with atypia & BDA \\
\hline Shape of acini/ducts & Round to oval & Round to oval & Distended, irregular, tubular \\
\hline Architecture & Flat, tufts or mounds & $\begin{array}{l}\text { Flat, tufts or mounds; no well-formed } \\
\text { bridges and papillary structures }\end{array}$ & Flat, tufts or mounds \\
\hline Stratification & Present in CCL with hyperplasia & May be present & $\begin{array}{l}\text { Mild stratification may be present, sometimes } \\
\text { (minimal) hyperplasia }\end{array}$ \\
\hline Conspicuous cell borders & + & + & - \\
\hline Luminal snouting & + & + & + \\
\hline Intracytoplasmic vacuoles & Rare & Rare & - \\
\hline Dimorphic cell population ('pale cells') & Rare & More frequent & - \\
\hline Myoepithelium & Inconspicuous & Inconspicuous & Conspicuous \\
\hline Overlapping nuclei & - & - & Slightly \\
\hline Nuclear arrangement & Regular & Regular or disorderly & Disorderly \\
\hline Nuclear size & Monotonous, small & Monotonous or variable; enlarged & Slightly variable, slightly to moderately enlarged \\
\hline Nuclear shape & Elongated/oval & Oval to round & Round to oval, slightly irregular \\
\hline Nucleoli & Inconspicuous; small & May be conspicuous & Small to prominent \\
\hline Position of nuclei & Basal & Usually central & Basal \\
\hline Microcalcifications & + & + & + \\
\hline Luminal secretion & + & + & + \\
\hline Luminal mucin & Rare & Rare & - \\
\hline Intralobular stroma & Normal & Normal & Expanded and mildly cellular, often myxoid \\
\hline Immunohistochemistry & CK5 negative & CK5 negative & CK5 mosaic in hyperplastic areas \\
\hline Molecular pathology & $16 q$ loss & $16 q$ loss & no $16 q$ loss \\
\hline
\end{tabular}

$+/-$, may be present; + , usually present; - , not present; CK, cytokeratin.

Because of the morphological differences and our own molecular findings in BDA showing no $16 \mathrm{q}$ loss, ${ }^{18}$ we propose that BDA is not part of this low nuclear grade breast neoplasia family but rather a benign polyclonal lesion. Potentially, the inclusion of BDA in the group of CCL without atypia has obscured the molecular and follow-up data in previous studies concerning CCLs without atypia. In fact, some lesions designated CCL in our own studies ${ }^{20}$ later had to be reclassified as BDA. The final problem with the current diagnostic criteria is the low reproducibility of diagnosing CCL with and without atypia. Although O'Malley achieved excellent agreement (kappa index 0.83 and higher) in diagnosing CCLs after a tutorial and in a selected case set, ${ }^{21}$ other groups found substantially lower kappa values $(0.27$ and 0.41). ${ }^{22-24}$ This indicates that differentiating between CCLs with and without atypia can be difficult. Because of the definable morphological characteristics of BDA, we propose to recognise $\mathrm{BDA}$ as a separate entity that can be differentiated from true CCL.

\section{PROPOSAL FOR MORPHOLOGICAL CRITERIA FOR BDA}

Based on the common denominator of the above studies and books, and integrating morphological and molecular features, we propose to define BDAs an enlarged terminal duct lobular unit with the following specific characteristics (see also table 1 and figure 1):

1. Tubular and often irregular acinic contours.

The acinic structures in BDA are distended, tubular and usually have irregular contours. This is immediately visible on overview. This is in contrast to CCLs, in which the contours of the acinic structures are usually round to oval.

2. Specialised intralobular stroma.

The intralobular stromal component in BDA is expanded and in the early phase more cellular and myxoid compared with the surrounding stroma of the breast. Also, this feature is easily visible on overview. In CCLs, the stroma is usually not expanded, the cellularity is similar to the surrounding stroma, and myxoid change is usually lacking.

3. Prominent myoepithelium.

In BDA, the myoepithelium is prominent, often with clear cytoplasm. The myoepithelial cells are cuboidal. This in contrast to CCLs in which the myoepithelium is flattened and often not even well visible.

4. Usual ductal hyperplasia-like luminal epithelium.

The luminal epithelium of BDA consists of columnar cells, usually with apical snouts. Especially in early proliferative lesions, the cells are slightly disorderly lined. There are no clear visible borders between the cells and slight nuclear overlap is often seen. The nuclei can be slightly to moderately enlarged with sometimes prominent nucleoli. All these changes are similar to what is seen in usual type hyperplasia. The larger and disorganised nuclei, with prominent nucleoli, can be confused with atypia as seen in CCLs with atypia. However, in contrast to BDA, the atypia in CCLs is apparent by a monotonous luminal cell population with conspicuous cell borders and lack of nuclear overlap. In the inactive (late stage) BDA, the nuclei are more orderly and hyperchromatic, usually without nucleoli.

As indicated, these features may slightly vary over the lifespan of a BDA. In the early (proliferative) phase, irregular acini dominate the lobular architecture, the intralobular stroma is more myxoid and less cellular, and the nuclei show more overlap and prominent nucleoli. In the late (inactive) phase, acini tend to adopt more rounded profiles and are lined by a simple, single layer of luminal cells without stratification. The cells have columnar or cuboidal shapes and minimal cytoplasm, apical or flattened. The nuclei are ovoid and the nucleoli are inconspicuous. The myoepithelium remains prominent, and the cellular intralobular stroma is still expanded but fibrotic rather than myxoid. The inactive phase of BDA is thereby more difficult to discriminate from columnar cell changes. 


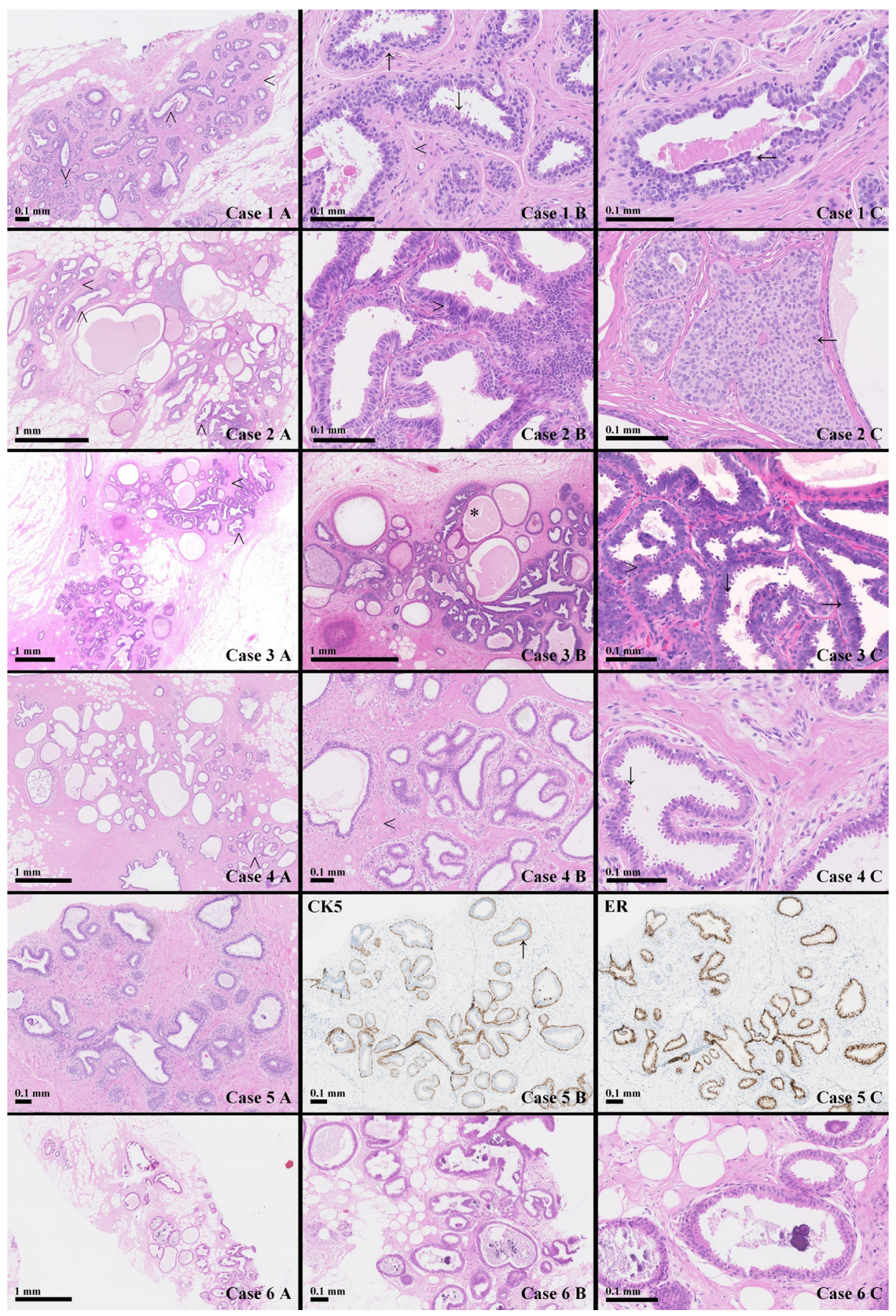

Figure 1 Morphological and immunohistochemical characteristics of blunt duct adenosis (BDA). Case 1: Classic BDA. 1A: Expanded terminal duct lobular unit (TDLU) with characteristic enlarged and irregular and tubular acini $(\wedge)$ and expanded and cellular intralobular stroma $(<)$. 1B: Prominent myoepithelium $(\uparrow)$, cellular intralobular stroma $(<)$, cytoplasmic tufting of luminal epithelial cells $(\downarrow)$. 1C: Small area of usual type ductal hyperplasia $(\leftarrow)$. Case 2: BDA with usual type hyperplasia. 2A: Very expanded TDLU with characteristic enlarged and irregular acini $(\wedge)$ in the upper left and lower right corner, but more rounded acini in the centre. 2B: Usual type ductal hyperplasia-like luminal epithelium with slight disordered cell orientation, nuclear overlap $(>)$ and inconspicuous cell borders. 2C: Clear focus of usual type ductal hyperplasia $(\leftarrow)$ in the centre. Case 3: BDA with apocrine metaplasia. 3A: Expanded TDLUs with enlarged and mostly irregular acini $(\wedge)$. 3B: Some rounded acini with apocrine metaplastic changes $\left({ }^{*}\right)$. $3 C$ : Close op of the luminal cells of BDA with classic luminal snouting $(\downarrow)$, inconspicuous cell borders, nuclear overlap $(>)$ and prominent nucleoli $(\rightarrow)$, in this context not to be interpreted as atypia. Case 4: Late phase BDA. 4A: TDLU with enlarged, largely rounded acini with in the lower left corner some irregular acinic contours. 4B: Intralobular stroma $(<)$ is still expanded but less cellular. 4C: The myoepithelium is not prominent in all acinic structures. Case 5: Classic BDA. 5A: Expanded TDLU with characteristic enlarged and irregular and tubular acini and expanded and cellular intralobular stroma. 5B: Prominent myoepithelium ( $\uparrow$ ) highlighted by CK5 staining, some solitary cytokeratin (CK) positive luminal cells. 5C: Oestrogen receptor (ER) staining showing 100\% positivity in this non-clonal proliferation. Case 6: Columnar cell lesion with atypia. 6A: Expanded TDLU with expanded regular rounded acini. 6B: Monotonous largely one-layered luminal epithelial proliferation that is partly flat, partly tufting. Several luminal calcifications. 6C: Conspicuous cell borders, monotonous round nuclei with nucleoli, cytoplasmic tufting. Inconspicuous myoepithelium. Fat cells between the acini, no intralobular fibrosis. 


\section{CONCLUSION}

BDA has been a controversial entity, since uniform diagnostic criteria for the diagnosis BDA were lacking, and not much was known about its molecular background. In this paper, we point out that BDA is mainly associated with benign breast lesions and rarely with other recognised precursor lesions. Further, $16 \mathrm{q}$ loss, which is the hallmark molecular event in the low nuclear grade breast neoplasia family, is lacking in well-defined BDA. We therefore propose that BDA is not a true precursor lesion in the low nuclear grade breast neoplasia family but rather a benign polyclonal lesion that may be diagnosed based on four wellrecognisable architectural and cytonuclear criteria. This may contribute to a better diagnosis of this common breast lesion in the differential diagnosis from CCL without atypia. Immunohistochemistry is of limited value, but molecular testing for $16 \mathrm{q}$ loss may help to make the distinction between BDA and CCL-type lesions in difficult cases. Follow-up data will have to show that the risk of subsequent progression to invasive cancer is indeed in the order of other benign lesions. ${ }^{25-27}$ Also, the reproducibility of diagnosis of BDA versus CCL based on these criteria will have to be studied.

\section{Take home massages}

- Blunt duct adenosis has been a controversial entity in the past.

- The absence of chromosome $16 q$ loss in blunt duct adenosis suggests it is not a true precursor lesion in the low nuclear grade breast neoplasia family.

- Blunt duct adenosis may be diagnosed (be distinguished from columnar cell lesions) based on four well recognisable architectural and cytonuclear criteria.

\section{Handling editor Runjan Chetty.}

Contributors All authors have contributed to this article.

Funding The authors have not declared a specific grant for this research from any funding agency in the public, commercial or not-for-profit sectors.

Competing interests None declared.

Patient consent for publication Not required.

Provenance and peer review Not commissioned; externally peer reviewed.

Open access This is an open access article distributed in accordance with the Creative Commons Attribution Non Commercial (CC BY-NC 4.0) license, which permits others to distribute, remix, adapt, build upon this work non-commercially, and license their derivative works on different terms, provided the original work is properly cited, appropriate credit is given, any changes made indicated, and the use is non-commercial. See: http://creativecommons.org/licenses/by-nc/4.0/.

ORCID iD

Paul J van Diest http://orcid.org/0000-0003-0658-2745

\section{REFERENCES}

1 Foote FW, Stewart FW. Comparative studies of cancerous versus noncancerous breasts. Ann Surg 1945;121:6-53.
2 Azzopardi JG. Problems in breast pathology. 1st edn. London: WB Saunders, 1979.

3 Shaaban AM, Sloane JP, West CR, et al. Histopathologic types of benign breast lesions and the risk of breast cancer: case-control study. Am J Surg Pathol 2002:26:421-30.

4 Kunju LP, Kleer CG. Significance of flat epithelial atypia on mammotome core needle biopsy: should it be excised? Hum Pathol 2007;38:35-41.

5 Hanbly AM, Ellis IO, Schnitt SJ. Who classification of tumours of the breast. 4th edn Lyon: IARC Press, 2012: 86-7.

6 Schnitt SJ, Morris EA, Vincent-Salamon A. including flat epithelial atypia. In: Breast tumours. 5th edn. Lyon: IARC Press, 2019: 15-17.

7 Brogi E. Adenosis and microglandular adenosis. In: Hoda SA, Brogi E, Koerner FC, et al, eds. Rosen's breast pathology. 4th ed. Philadelphia, PA: Lippincott Williams \& Wilkins, 2014: 183-212

8 Koerner F. Conventional Ductal Proliferations. In: Diagnostic problems in breast pathology. Philadelphia, PA, 2009: 15-83.

9 Lerwill MF. Flat Epithelial Atypia. In: Palazzo JP, ed. Difficult diagnosis in breast pathology. New York: Demos Medical Pub, 201188-113.

10 Dabbs DJ. Fibrocystic changes and Usual Epithelial Hyerplasia of Ductal Type. In: Breast pathology. 2nd ed. Philadelphia, PA: Elsevier, 2017: 373-95.

11 Böcker W, Hungermann D, Tio J, et al. [Flat epithelial atypia]. Pathologe 2009:30:36-41.

12 Koerner FC, Oyama T, Maluf H. Morphological observations regarding the origins of atypical cystic lobules (low-grade clinging carcinoma of flat type). Virchows Arch 2001;439:523-30.

13 Carley AM, Chivukula M, Carter GJ, et al. Frequency and clinical significance of simultaneous association of lobular neoplasia and columnar cell alterations in breast tissue specimens. Am J Clin Pathol 2008;130:254-8.

14 Brandt SM, Young GQ, Hoda SA. The "Rosen Triad": tubular carcinoma, lobular carcinoma in situ, and columnar cell lesions. Adv Anat Pathol 2008;15:140-6.

15 Oyama T, lijima K, Takei H, et al. Atypical cystic lobule of the breast: an early stage of low-grade ductal carcinoma in-situ. Breast Cancer 2000;7:326-31.

16 Simpson PT, Gale T, Reis-Filho JS, et al. Columnar cell lesions of the breast: the missing link in breast cancer progression? A morphological and molecular analysis. Am J Surg Pathol 2005;29:734-46.

17 Go EML, Tsang JYS, Ni Y-B, et al. Relationship between columnar cell changes and low-grade carcinoma in situ of the breast--a cytogenetic study. Hum Pathol 2012:43:1924-31.

18 de Boer M, Verschuur-Maes AHJ, Buerger $\mathrm{H}$, et al. Role of columnar cell lesions in breast carcinogenesis: analysis of chromosome 16 copy number changes by multiplex ligation-dependent probe amplification. Mod Pathol 2018;31:1816-33.

19 Bürger $H$, de Boer $M$, van Diest PJ, et al. Chromosome $16 \mathrm{q}$ loss--a genetic key to the understanding of breast carcinogenesis. Histol Histopathol 2013:28:311-20.

20 Verschuur-Maes AHJ, Witkamp AJ, de Bruin PC, et al. Progression risk of columnar cell lesions of the breast diagnosed in core needle biopsies. Int J Cancer 2011;129:2674-80.

21 O'Malley FP, Mohsin SK, Badve S, et al. Interobserver reproducibility in the diagnosis of flat epithelial atypia of the breast. Mod Pathol 2006;19:172-9.

22 Gomes DS, Porto SS, Balabram D, et al. Inter-observer variability between general pathologists and a specialist in breast pathology in the diagnosis of lobular neoplasia, columnar cell lesions, atypical ductal hyperplasia and ductal carcinoma in situ of the breast. Diagn Pathol 2014;9:121

23 Haupt B, Schwartz MR, Xu Q, et al. Columnar cell lesions: a consensus study among pathology trainees. Hum Pathol 2010;41:895-901.

24 Tan PH, Ho BC-S, Selvarajan S, et al. Pathological diagnosis of columnar cell lesions of the breast: are there issues of reproducibility? J Clin Pathol 2005;58:705-9.

25 Boulos Fl, Dupont WD, Simpson JF, et al. Histologic associations and long-term cancer risk in columnar cell lesions of the breast: a retrospective cohort and a nested casecontrol study. Cancer 2008;113:2415-21.

26 Boulos Fl, Dupont WD, Schuyler PA, et al. Clinicopathologic characteristics of carcinomas that develop after a biopsy containing columnar cell lesions: evidence against a precursor role. Cancer 2012;118:2372-7.

27 Aroner SA, Collins LC, Schnitt SJ, et al. Columnar cell lesions and subsequent breast cancer risk: a nested case-control study. Breast Cancer Res 2010;12:R61. 